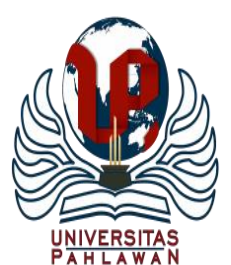

Edukatif : Jurnal Ilmu Pendidikan Volume 3 Nomor 6 Tahun 2021 Halm 3531 - 3537

EDUKATIF: JURNAL ILMU PENDIDIKAN

Research \& Learning in Education

https://edukatif.org/index.php/edukatif/index

\title{
Kepemimpinan Kepala Sekolah di Sekolah Menengah Pertama
}

\author{
Hidayatul Riski $^{1 凶}$, Rusdinal $^{2}$, Nurhizrah Gistituati ${ }^{3}$ \\ Universitas Negeri Padang, Indonesia ${ }^{1,2,3}$ \\ E-mail : hidayatulriski06@gmail.com ${ }^{1}, \underline{\text { Rusdinal@fip.unp.ac.id }}^{2}, \underline{\text { Icha_yp@yahoo.com }}^{3}$
}

\begin{abstract}
Abstrak
Kepemimpinan transformasional kepala sekolah merupakan kepemimpinan yang melakukan pekerjaan dengan cara yang berbiwaba, memahami kondisi sekolah, memberikan semangat kepada warga sekolah dalam menjalankan. Tujuan penelitian ini adalah untuk mengambarkan kepemimpinan kepala sekolah SMPN. Metode pengumpulan data menggunakan data deskriptif kualitatif. Hasil penelitian mengambarkan bahwa kepemimpinan kepala sekolah mendukung aktivitas mendukung semua aktivitas yang dilakukan oleh kepala sekolah, supel mudah menerima pendapat bawahan dan mampu memberikan perubahan di dalam lingkungan sekolah, dengan cara memantau, menilai aktivitas yang dilakukan di sekolah, mampu memberikan perubahan menghasilkan lulusan yang berkualitas dan menjadikan sekolah yang dipimpin menjadi sekolah paporit bahwa warga masayarakat sekitarnya dan kepala sekolah dapat dijadikan teman bagi warga sekolah ketika ada warga sekolah yang menghadapi permasalahan, guru tidak merasa segan atau malu untuk bertanya dan menjelaskan permasalahan yang dihadapi.
\end{abstract}

Kata Kunci: kepemimpinan transformasional.

\begin{abstract}
Principal Transformational Leadershi Abstract The principal's transformational leadership is leadership who does work in an authoritative way, understands the condition of the school, gives encouragement to the school community in carrying out. The purpose of this study was to describe the leadership of the SMPN principal. The data collection method used descriptive qualitative data. The results of the study illustrate that the principal's leadership supports activities that support all activities carried out by the principal, is sociable, easy to accept subordinates' opinions and is able to provide changes in the school environment, by monitoring, assessing activities carried out in schools, being able to provide changes to produce quality graduates. and make the school that is led into a paporit school that the surrounding community and the principal can be used as friends for school residents when there are school members who face problems, teachers do not feel shy or embarrassed to ask questions and explain the problems they face.
\end{abstract}

Keywords: transformational leadership.

Copyright (c) 2021 Hidayatul Riski, Rusdinal,, Nurhizrah Gistituati

$\triangle$ Corresponding author

Email : hidayatulriski06@gmail.com

DOI : https://doi.org/10.31004/edukatif.v3i6.944

ISSN 2656-8063 (Media Cetak)

ISSN 2656-8071 (Media Online) 
3532 Kepemimpinan Kepala Sekolah di Sekolah Menengah Pertama - Hidayatul Riski, Rusdinal, Nurhizrah Gistituati

DOI : https://doi.org/10.31004/edukatif.v3i6.944

\section{PENDAHULUAN}

Mendidik bangsa adalah membuka amanat UUD 1945 yang harus dilaksanakan oleh pemerintah dan masyarakat. Dengan kecerdasan, berbagai masalah dan tantangan dapat dengan mudah diatasi. Kecerdasan dapat diperoleh melalui pendidikan formal dan nonformal. Berbagai seminar dan melalui media massa dapat dilihat bahwa banyak negara maju seperti Singapura, Malaysia, Jepang, Korea yang memiliki sumber daya alam yang terbatas mampu membangun masyarakat yang sejahtera. Negara-negara tersebut sangat memperhatikan kualitas pendidikan sehingga menghasilkan sumber daya manusia yang berkualitas. Bermacam-macam jenjang pendidikan yang diterapkan banyak negara sebagian besar dibagi dalam 3 tahap yaitu dimulai dari pendidikan dasar sampai pendidikan tinggi. Sebagai suatu sistem pendidikan mempunyai berbagai subsistem. Subsistem yang dominan mempengaruhi mutu pendidikan adalah tenaga pendidik baik di tingkat dasar maupun perdosenan tinggi, karena tenaga pendidik yang dalam fungsi dan tugasnya berinteraksi langsung dengan peserta didik. Pendidikan adalah suatu usaha yang dilakukan secara sadar dan terencana untuk mewujudkan suasana belajar ideal dan pembelajaran ideal, agar peserta didik secara aktif mengembangkan potensi yang ada dalam dirinya untuk memiliki kekuatan spiritual keagamaan, pPengendalian diri, kepribadian, Kecerdasan, Akhlak yang mulia, serta keterampilan lainnya yang diperlukan dirinya, masyarakat, bangsa dan negara(Al Faruq \& Supriyanto, 2020).

Lembaga pendidikan selalu mengalami perkembangan di sekolah dapat membawa perubahan dilingkungan sekolah tersebut,salah satu aspek budaya sekolah, iklim sekolah, komunikasi, kinerja guru serta peraturan yang ada di dalam sekolah, perkembangan sekolah hendaknya membawa perubahan yang positif terhadap lingkungan sekolah dalam hal ini guru merasa senang dan nyaman di sekolah karena selalu mendapatkan dukungan dari kepala sekolah dari setiap aktivitas yang dilakukan berkaitan dengan mutu pembelajaran di sekolah Gaya kepemimpinan ialah pola- pola perilaku pemimpin yang digunakan untuk mempengaruhi aktivitas orang-orang yang dipimpin untuk mencapai tujuan dalam suatu situasi organisasinya yang dapat berubah (Azizzah, 2018) (Yuningsih \& Herawan, 2015) (Hakim \& Yahya, 2014) Kepemimpinan transformasional kepala sekolah teknik kepemimpinan yang dilakukan bawahan yang dipimpin dijadikan patner kerja, bukan antara atasan dan bawahan, saling memberikan motivasi, membangun kerjasama, dalam rangka meningkatkan kinerja guru. Jika kepala sekolah yang transformasi mampu memberikan perubahan kepada sekolah terutama dalam peningkatan mutu pembelajaran yang dihalatkan dari mutu lulusan yang diterima sekolah menengah atas yang paforit dan berkualitas, gaya kepemimpinan ini cukup memberikan perubahan yang sangat singnifikan dalam meningkatkan mutu sekolah dan memberikan semangat kepada warga sekolah untuk berprestasi sesuai dengan bidang kahlian dan kemampuan masing-masing. Kepala sekolah selalu terbuka dari setia permasalahan yang dihadapi warga sekolah. Masalah yang sering muncul adalah kepemimpinan dari kepala sekolah. Hal ini dapat dilihat dari kepala sekolah kurang memberikan pengarahan kepada guru yang menyangkut permasalahan sekolah, kurang adanya pendekatan kepala sekolah kepada guru, sehingga guru kurang bersemangat dalam mencapai tujuan organisasi, kurangnya upaya kepala sekolah dalam mengubah kesadaran yang dimiliki oleh guru. Hal ini tentu saja dapat membuat kualitas pembelajaran yang ada disekolah menjadi menurun.

Berdasarkan pra-survei yang dilakukan, kepala sekolah SMP 03 Solok Selatan telah bisa menjalankan tugasnya sesuai dengan tupoksi beliau menjadi kepala sekolah. Beberapa hal yang masih kurang adalah terkait hubungan antara kepala sekolah, guru dan staf dalam etos kerja. Aktivitas guru dan staf dalam melaksanakan tugasnya masih dipengaruhi oleh kepemimpinan kepala sekolah. Kepemimpinan seorang kepala sekolah berdampak sangat besar dalam meningkatkan kinerja guru yang memunculkan etos kerja dari guru dan staf seperti semangat dalam mengerjakan tugasnya masing-masing, berdedikasi tinggi terhadap sekolah, menjunjung tinggi kebersamaan dalam bekerja dan sama sama mencapai tujuan sekolah. Sehingga 


\section{Kepemimpinan Kepala Sekolah di Sekolah Menengah Pertama - Hidayatul Riski, Rusdinal, Nurhizrah Gistituati \\ DOI : https://doi.org/10.31004/edukatif.v3i6.944}

berdasarkan penjelasan di atas, maka penting bagi peneliti untuk mengkaji lebih dalam terkait pengaruh gaya kepemimpina transformasional terhadap etos kerja guru dan staf di SMP 03 Solok Selatan.

Kepemimpinan yang transformasional yang membangun keyakinan kelompok yang tidak terlepas dari nilai-nilai dan budaya sekolah,kepemimpinan ini selalu mefeflasikan kebutuhan nilai dengan memberikan keyakinan kepala kelompok atau warga sekolah untuk berkembang, yang selalu mengkolabariskan gaya kepemimpinan yang mengayomi dan menjadikan bawahan sebagai patner kerja bukan menaggapa bawahan sebagai pekerja, dijadikan tempat diskusi dan membangun keyakinan bahwa setiap warga sekolah mempunyai pendapat yang berbeda dalam mengembangkan potensi yang ada. Menurut Bass ((Bass, 2005)) kepemimpinan transformasional merasa adanya kepercayaan yang diberikan oleh bawahan yang terlihat dari kesetiaan, kekaguman dan adanya rasa hormat pemimpinya dan bawahannya sehinga bawahan dalam melaksanakan pekerjaan tidak lagi dibawa tekanan yang begitu berat. (1) mendorong pengikutnya untuk lebih mementingkan tim atau organisasi dari pada kepentingan dirinya sendiri; (2) mengaktifkan kebutuhan pengikutnya pada level yang lebih tinggi dan (3) membuat pengikutnya lebih sadar mengenai arti penting hasil suatu pekerjaan yang dilakukan.

\section{METODE PENELITIAN}

Penelitian deskripsi mengambarkan objek penelitian apa adanya pada saat menemukan data dilapangan. Hal ini sesuai dengan pendapat ((Arikunto, 2010)) penelitian deskriptif dapat diartikan sebagai penyelidikan situasi dan kondisi yang dilaporkan dalam bentuk laporan penelitian Populasi di dalam penelitian ini adalah kepala sekolah yang langsung dijadikan sampel penelitian teknik pengambilan sampel menggunakan metode sensus (Arikunto, 2010)). Informan di dalam penelitian ini adalah guru, siswa dan kepala sekolah. Teknik pengumpulan data dapat dilakukan dengan wawancara, kuisioner dan angket. Teknik analisis data menggunakan data kualitatif dimulai dari pengumpulan data, menganalisis data dan menarik kesimpulan

\section{HASIL DAN PEMBAHASAN PENELITIAN}

Gaya kepemimpinan kepala sekolah ditentukan dengan strategi yang digunakan, gaya kepemimpinan kepala sekolah memberikan pengaruh yang positif dalam mengembangkan budaya sekolah, kepala sekolah yang transformative adalah kepala sekolah yang mampu memberikan perubahan di sekolah, mampu membangun komunikasi antara kepala sekolah dengan guru, guru sesama guru dan guru dengan siswa di dalam proses pembelajaran, kepala sekolah menjadi panutan bagi warga sekolah. Kepala sekolah merupakan orang yang dikagumi dan disenggani oleh guru disekolah dan warga sekolah dan kepala sekolah transformatif mampu mengambil keputusan yang bijaksana sesuai dengan kesepakatan bersama.

Kepemimpinan transformasional adalah tindakan pemimpin dalam memperngaruhi bawahannya sehingga memiliki kemauan untuk bekerja dalam upaya pencapaian tujuan organisasi yang terdiri dari tiga komponen yaitu karisma, pertimbangan, individual, dan stimulasi intelektual motivasi (Wahidin, 2020). Kepala sekolah yang transformasional mampu memberikan semangat kepada warga sekolah melalui berbagai kegiatan seperti diskusi, memperhatikan semua kebutuhan guru di sekolah dan kepala sekolah memberikan nasehat secara langsung, jika ada guru atau warga sekolah melakukan kesalahan,peneguran secara langsung dengan cara memanggil guru untuk masuk kedalam ruang kepala dan kepala sekolah meminta penjelasan langsung dari guru yang bersangkutan. Hal ini dilakukan oleh kepala sekolah agar informasi yang diterima tidak salah sasaran dan kepala mendapatkan informasi yang pasti dari guru itu sendiri. Ada beragam gaya kepemimpinan yang digunakan, namun sebagian besar model kepemimpinan mengadopsi gaya transformasional dan transaksional (Verawati Wote \& Patalatu, 2019). 


\section{Kepemimpinan Kepala Sekolah di Sekolah Menengah Pertama - Hidayatul Riski, Rusdinal, Nurhizrah Gistituati \\ DOI : https://doi.org/10.31004/edukatif.v3i6.944}

Kepala sekolah di SMP Negeri 03 Solok Selatan di sekolah selatan termasuk kedalam unsur bisa mempengaruhi bawahannya, mengatur, besikap baik dan bijak dalam menentukan program kerja sekolah, melakukan pendekatan dengan memberikan motivasi terbuka pada staf atau guru yang ada di sekolah. Memberikan tanggungjawab sesuai dengan kemampuan yang dimiliki guru yang bersangkutan dan kepala sekolah SMP Negeri 03 Solok Selatan lebih fokus dalam peningkatan mutu peserta didik baik secara akademik maupun non akademik. Mutu dalam bidang non akademik dalam hal ini kepala sekolah membangun kepercayaan diri kepada semua civitas sekolah dalam melaksanakan tugas, selama ini pola kepemimpinan yang dilakukan oleh kepala sekolah belum mampu memberikan kepercayaan penuh kepada guru dalam melaksanakan tugas. Peran utama yang dilakukan kepala sekolah dengan membangun kepercayaan diri guru dan civitas sekolah. Kepala sekolah memberikan kebebasan kepada guru dalam mengembangkan diri dan membatu melaksanakan tugas sekolah secara penuh tanpa ada rasa ragu.

Menurut (Bernard M. Bass \& Ronald E. Riggio, 2006) pemimpin transformasional memberdayakan pengikutnya dan memperhatikan kebutuhan individu dan pengembangan pribadi mereka, membantu pengikut untuk mengembangkan potensi kepemimpinan mereka sendiri (Verawati Wote \& Patalatu, 2019). Kepemimpinan transformasional dalam penelitian ini sebagai unsur menanamkan dan mendorong seorang guru untuk bersikap kritis terhadap pendapat, merangsang guru untuk lebih kreatif, inovatif, serta lebih meningkatkan harapan dan meingkatkan diri pada visi serta mengatasi tantangan dan hambatan dalam upaya untuk mencapai tujuan pendidikan (Kurniawati et al., 2017). Kepala sekolah selalu memperhatikan guru secara personal sehingga kepala sekolah memahami kondisi dan karakter masing-masig guru yang ada di sekolah yang berperan sebagai motivator dan berperan sebagai pelatih, dan bertanggung jawab terhadap perkembangan kompetensi guru dengan mengikut sertakan guru mengikuti pelatihan-pelatihan terutama dalam peningkatan kompetensi profesionalisme guru dan menyiapkan sarana dan prasarana pembelajaran sehingga suasana belajar lebih menyenangkan dan pembagian kerja terhadap bawahan sesuai dengan bidang keahlian dan kompetensi yang dimiliki dan tidak merasa segan memberikan penghargaan bagi guru yang berprestasi baik dari segi akademik maupun non akademik. Hal ini sejalan dengan penelitan (Husnawati, 2019), (Ju et al., 2020) kepala sekolah yang transformasional mampu menghargai dan membimbing guru mencapai kompetensi dalam peningkatan mutu pembelajaran selalu berusaha mengispirasi warga sekolah sekolah termasuk guru agar lebih meningkatkan profesionalisme dan memberikan contoh disiplin waktu, kepala sekolah menjadi teladan dengan datang kesekolah tepat waktu hal ini secara tidak langsu kepala sekolah membangun budaya disiplin di lingkungan sekolah dan membangun budaya peduli lingkungan sebelum siswa memasuki kelas diminta dulu membersihkan halaman sekolah jika ada sampah yang berserakan di halaman sekolah, diambil dan dimasukkan kedalam tempat sampah yang sudah disediakan.

Kepala sekolah melalui teguran secara tidak langsung dengan cara memberikan pendekatan kepada guru yang bersangkutan dengan cara dan teknik yang bijaksana, kepala sekolah tranformasional mampu memberikan kebebasan kepada guru untuk kreatif terutama dalam mengelola pembelajaran, kepala akan merasa senang jika guru mampu berkreasi sesuai dengan kemampuannya, kepala sekolah tidak membunuh karakter guru dan siswa bahkan mendukung dari setiap kegiatan yang dilakukan oleh warga sekolah dalam hal ini aktivitas yang dilakukan tentunya dapat mendukung aktivitas warga sekolah. Inti dari kepemimpinan transformasional adalah pimpinan mampu memberikan inspirasi kepada bawahannya mencapai kemungkinankemungkinan yang belum terpikirkan oleh guru sebelumnya, kepala sekolah menyeimbangkan tujuan pribadi dan organisasi, kepala sekolah memandang ancaman sebagai peluang untuk maju dan berkembang, di dalam memberikan nasehat kapala sekolah selalu membangkaitkan semangat guru, kepala sekolah sebagai roll model, terbiasa selalu optimis yang pesimis dihilangkan, memberikan dukungan dari setiap kegiatan yang dilakukan oleh guru, menciptakan budaya kerja yang menyenangkan dan menjadi mentor kepada semua warga sekolah. 


\section{Kepemimpinan Kepala Sekolah di Sekolah Menengah Pertama - Hidayatul Riski, Rusdinal, Nurhizrah Gistituati \\ DOI : https://doi.org/10.31004/edukatif.v3i6.944}

Kepemimpinan transformasional kepala sekolah berpengaruh positif terhadap peningkatan kinerja guru. Ini berarti semakin efektif kepemimpinan transformasional kepala sekolah, maka semakin meningkat kinerja guru; 2) Budaya kerja berpengaruh positif terhadap kinerja guru. Ini berarti semakin kondusif budaya kerja, maka semakin meningkat kinerja guru; 3) Kepemimpinan transformasional kepala sekolah dan budaya kerja berpengaruh positif terhadap kinerja guru. Ini berarti semakin efektif gaya kepemimpinan transformasional kepala sekolah dan semakin kondusif budaya kerja sekolah, maka semakin meningkat kinerja guru. Pemimpin disekolah mampu memposisikan diri sesuai dengan menempatkan diri sesuai dengan situasi dan kondisi dimana kepala sekolah sebagai seorang tranformasi yang selalu memotivasi dan menjadi Pembina bagi guru di sekolah. Dalam situasi dan kondisi tertentu kepala sekolah menjadi seorang yang inpirator yang mampu memberikan perubahan bagi perkembangan sekolah terutama di SMP Negeri 03 Solok Selatan.

Agen perubahan adalah kemampuan pemimpin untuk selalu berada di depan untuk mengadakan perubahan-perubahan dan mengembangkan sumber daya yang ada dalam organisasi ke arah yang lebih baik. Dimensi agen perubahan memiliki indikator: mengembangkan SDM, mengembangkan sistem, pengembangan organisasi, dan alih teknologi. Percaya diri adalah keyakinan seorang pemimpin akan kemampuan dan kelebihan yang dimiliki untuk dapat dimanfaatkan dalam menggerakkan organisasi guna mencapai tujuan yang telah ditetapkan. Dimensi kepercayaan diri memiliki indikator: keyakinan, kewibawaan dan kerelaan berkorban. Kharismatik adalah kemampuan pemimpin dalam mempengaruhi, memberikan. semangat, optimisme, dan dijadikan teladan serta diikuti oleh para bawahn dengan sukarela. Dimensi karismatik memiliki inidkator: membangkitkan semangat kerja, membangkitkan optimisme, menjadi teladan. Empatik adalah sifat seorang pemimpin yang selalu dapat memberikan perhatian. kepada bawahan, serta dapat merasakan perasaan, kesedihan, kegembiraan serta harapan dan keinginan dan kebutuhan bawahan. Dimensi empatik memiliki indikator: memperhatikan kebutuhan bawahan, memberikan penghargaan, merasakan penderitaan bawahan, merasakan kegembiraan bawahan.

Sejalan dengan hasil penelitian (Kuswaeri, 2019) (Kurniawati et al., 2017) Penerapan gaya kepemimpinan transfomasional Kepala sekolah terlihat pada: kemampuan merumuskan visi, misi, dan program sekolah, menjadi agen perubahan, memiliki kharisma, memiliki empatik, merangsang intelektualitas dan menumbuhkan kreativitas, memberi kesempatan kepada semua unsur di sekolah. Penerapan kepemimpinan transformasional kepala sekolah membawa pengaruh kepada menyelenggarakan proses pembelajaran yang secara profesional. Tercipta budaya dan iklim sekolah yang kondusif, tercapainya prestasi belajar siswa yang tinggi. Kepala sekolah harus mengelola perubahan agar mengarah pada pembaharuan. Kegiatan pembaharuan pendidikan berupaya melakukan pembenahan-pembenahan pendidikan guna mencapai hasil yang lebih baik dari hasil-hasil sebelumnya. Melalui stimulasi intelektual pemimpin dapat merangsang tumbuhnya inovasi dan cara-cara baru dalam menyelesaikan masalah (Ju et al., 2020) Ciri kepemimpinan transformasional Idealized influence Kepala Sekolah memiliki beberapa ciri yang pertama Kepala Sekolah mampu menjadi teladan yang baik bagi warga sekolahnya karena Kepala Sekolah selalu datang ke sekolah tepat waktu, sehingga memberikan contoh langsung pada guru dan peserta didik (Rahayu, 2018). Menurut teori Kouzes dan Posner, pemimpin transformasional adalah pem- impin yang harus mampu memberikan contoh kepada bawahannya, menjadikan panu- tan bagi bawahannya, dapat menginspirasi- kan untuk para karyawan, mengarahkan bawahan ke arah yang lebih jauh, memberikan motivasi yang kuat bagi karyawan agar kinerja karyawan tersebut bagus, serta siap untuk menerima tantangan ke depannya bagi pemimpin, karyawan serta seluruh isi di suatu organisasi. Jadi dapat dikatakan bahwa kepemimpinan transformasional dapat didefinisikan sebagai kemampuan pemimpin dalam meningkatkan kinerja karyawannya. Dengan sikap kepemimpinan yang ditunjukkan oleh kepala sekolah, maka kinerja para guru pun akan meningkat dan dengan begitu para guru akan selalu meningkatkan produktivitas kerja di sekolah tersebut (Putra Rustamaji et al., 2017),(Suyitno, 2021) Kepemimpinan tranformasional adalah berfokus pada hubungan yang terbentuk antara pemimpin dan pengikutnya. Pemimpin memotivasi dan mengilhami atau menginspirasi orang dengan 
3536 Kepemimpinan Kepala Sekolah di Sekolah Menengah Pertama - Hidayatul Riski, Rusdinal, Nurhizrah Gistituati

DOI : https://doi.org/10.31004/edukatif.v3i6.944

membantu anggota kelompok memahami potensinya untuk kemudian ditransformasikan menjadi perilaku nyata dalam rangka penyelesaian tugas pokok dan fungsi dalam kebersamaan. Pemimpin transformasional terfokus pada kinerja anggota kelompok, tapi juga ingin setiap orang untuk memenuhi potensinya. Pemimpin transformasional biasanya memiliki etika yang tinggi dan standar moral (Inayatillah et al., 2016).

\section{KESIMPULAN}

Kepemimpinan transformasional kepala sekolah adalah kepemimpinan yang mampu memberikan perubahan dengan pola dan cara yang sederhana namun semua bawahan merasa dihargai dan disegani, dalam hal ini kepala sekolah menjadikan warga sekolah adalah patner kerja, bukan menggap bawahan anak buah yang dapat diperintah sesuka hati pimpinan, namun menjadikan warga sekolah sebagai anggota disekolah yang mampu berkreasi dan membangun motivasi, kreaktivitas dan imajinasi sesuai dengan bidang keahlian dan keilmuan yang dimiliki. Kepala mampu memberikan perubahan dalam meningkatkan mutu dan kualitas pembelajaran disekolah dengan cara yang tidak diduga sebelumnya. Kepala sekolah menjadi roll model di dalam melaksanakan kepemimpinan, yang dapat dijadikan panutan bagi guru terutama dalam pengam bilan keputusan secara bijaksana dan kepala sekolah memberikan kebebasan kepada warga sekolah untuk berkreasi terutama dalam peningkatan nama sekolah dan mutu pendidikan di SMP 03 Solok Selatan.

\section{UCAPAN TERIMAKASIH}

Ucapan terimakasih saya sampaikan kepada dosen pembimbing mata kuliah kepemimpinan Prof. Dr. Rusdinal, M.Pd dan Prof. Dr. Nurhizrah Gistituati,.M.Ed.yang telah membimbing dan mengarahkan terutama dalam penulisan artikel ini.

\section{DAFTAR PUSTAKA}

Al Faruq, M. H., \& Supriyanto, S. (2020). Kepemimpinan Transformasional Kepala Sekolah Dalam Meningkatkan Mutu Guru. Jurnal Dinamika Manajemen Pendidikan, 5(1), 68. Https://Doi.Org/10.26740/Jdmp.V5n1.P68-76

Arikunto, S. (2010). Arikunto, Suharsismi. 2010. Prosedur Penelitian Suatu Pendekatan Praktek. Jakarta: PT. Rineka Cipta.

Azizzah, F. (2018). Pengarauh Gaya Kepemimpinan Transformasional Kepala Sekolah Dan Motivasi Guru Terhadap Kinerja Guru Di SMA Al-Islam 1 Surakarta. Pendidikan Ekonomi, 1-15.

Bernard M. Bass, \& Ronald E. Riggio. (2006). Transformational Leadership, Second Edition Lawrence Erlbaum Associates. Lawrence Associates. Https://Www.Academia.Edu/34579754/Bernard_M._Bass_Ronald_E._Riggio_Transformational_Leader ship_Second_Edition_Lawrence_Erlbaum_Associates_2005_

Hakim, A. R., \& Yahya, M. (2014). Analisis Pengaruh Gaya Kepemimpinan, Motivasi Kerja, Dan Kompensasi Terhadap Kinerja Guru (Studi Kasus Di Sma Ppmi Assalam Surakarta). Jurnal Pendidikan Ilmu Sosial, 24(1), 67-77.

Husnawati. (2019). Efektivitas Kepimpinan Transformasi Kepala Sekolah. Journal Of Chemical Information And Modeling, 53(9), 1689-1699.

Inayatillah, S., Abdurakhman, O., \& Aliyyah, R. R. (2016). Pengaruh Kepemimpinan Transformasional Kepala Sekolah Terhadap Kinerja Guru Di Ma Miftahul Huda Dan Ma Fathan Mubina The Effect Of Transformational Leadership Principal On The Teacher Performance At Ma Miftahul Huda And Ma Fathan Mubina. 5(1), 23-31. 
3537 Kepemimpinan Kepala Sekolah di Sekolah Menengah Pertama - Hidayatul Riski, Rusdinal, Nurhizrah Gistituati

DOI : https://doi.org/10.31004/edukatif.v3i6.944

Ju, J., Wei, S. J., Savira, F., Suharsono, Y., Aragão, R., Linsi, L., Editor, B., Reeger, U., Sievers, W., Michalopoulou, C., Mimis, A., Editor, B., Ersbøll, E., Groenendijk, K., Waldrauch, H., Waldrauch, H., Bader, E., Lebhart, G., Neustädter, C., ... Saillard, Y. (2020). Kepemimpinan Transformasional Kepala Sekolah Dalam Meningkatkan Profesionalisme Guru Di SMP Islam Thoriqul Huda Cekok Babadan Ponorogo. Journal Of Chemical Information And Modeling, 43(1), 7728. Https://Online210.Psych.Wisc.Edu/Wp-Content/Uploads/PSY-210_Unit_Materials/PSY210_Unit01_Materials/Frost_Blog_2020.Pdf\%0Ahttps://Www.Economist.Com/SpecialReport/2020/02/06/China-Is-Making-Substantial-Investment-In-Ports-And-PipelinesWorldwide\%0Ahttp://

Kurniawati, S., Sukmawati, \& Chiar, M. (2017). Pengaruh Kepemimpinan Transformasional Kepala Sekolah Dan Iklim Organisasi Sekolah Terhadap Kinerja Guru. Jurnal Pendidikan Dan Pembelajaran Khatulistiwa, 6(2), 1-12.

Kuswaeri, I. (2019). Artikel Gaya Kepemimpinan Transformasional Kepala Sekolah. Tarbawai, 2(02), 1-13. Https://Doi.Org/10.31227/Osf.Io/C8st6

Putra Rustamaji, A. C., Purwana, D., \& Yohana, C. (2017). Gaya Kepemimpinan Transformasional Kepala Sekolah Dan Kinerja Guru SMK Swasta Di Jakarta Timur. Jurnal Pendidikan Ekonomi Dan Bisnis (JPEB), 5(2), 148-161. Https://Doi.Org/10.21009/Jpeb.005.2.3

Rahayu, R. S. (2018). Implementasi Kepemimpinan Transformasional Kepala Sekolah Dasar Negeri. Jurnal Manajemen Dan Supervisi Pendidikan, 2(3), 192-201. Https://Doi.Org/10.17977/Um025v2i32018p192

Riggio, B. M. B. R. E. (2005). Transformasional Leadership. Psychology Press.

Suyitno. (2021). Analisis Kepemimpinan Kepala Sekolah , Penerapan Disiplin Dan Pengawasan Terhadap Etos Kerja Suyitno. Edukatif, 3(3), 728-737.

Verawati Wote, A. Y., \& Patalatu, J. S. (2019). Pengaruh Gaya Kepemimpinan Transformasional Dan Kepuasan Kerja Terhadap Kinerja Guru Sekolah Dasar. Jurnal Ilmiah Sekolah Dasar, 3(4), 465. Https://Doi.Org/10.23887/Jisd.V3i4.21782

Wahidin, W. (2020). Pengaruh Kepemimpinan Transformasional Kepala Sekolah Dan Motivasi Kerja Terhadap Kinerja Guru SMK Negeri Jakarta Utara. Tadbir : Jurnal Studi Manajemen Pendidikan, 4(1), 151. Https://Doi.Org/10.29240/Jsmp.V4i1.1274

Yuningsih, E., \& Herawan, E. (2015). Kepemimpinan Transformasional Kepala Sekolah Dan Iklim Sekolah Terhadap Sekolah Efektif Pada Sd Negeri Di Purwakarta. Jurnal Administrasi Pendidikan UPI, 22(2), 81-92. Https://Doi.Org/10.17509/Jap.V22i2.5390 